\title{
Testemunho: memória da praça, sinaleira, carroça, latinha ${ }^{1}$
}

Maria Luiza Martini*

\begin{abstract}
Resumo: Este artigo trata do imaginário de crianças e adolescentes em situação de rua, numa perspectiva de longa duração, a partir do conto de fadas, em grupos focais, indo aos lugares onde esta população atua, dando preferência a entrevistas por comentário. Reúne correlações de variáveis de questionários estruturados, descrições de elementos culturais constituintes de seus quadros sociais de memória.
\end{abstract}

Abstract: This article is about the imaginary of street children. Working from fairy tales, in focal groups, going to the places where this population acts, giving preference to interviews and comments; this work collects correlations of variables from structured questionnaires, descriptions of cultural elements constituents of the social frameworks of memory.

Palavras-chave: Memória. Produção cultural de referência. Situação de rua.

Key words: Memory. Cultural production of reference. Street situation.

No limite do questionário estruturado e semi-estruturado, procuramos construir questões que envolvessem o imaginário e elementos culturais. Além disso, Miriam Lemos, primeira diretora da Escola Aberta em Porto Alegre, e eu, historiadora, professoras e pesquisadoras da UFRGS, realizamos um segmento de trabalho qualitativo, privilegiando vários tipos de entrevista.

A fonte histórica mais antiga é o testemunho, ver, ouvir, experimentar, ouvir dizer (próximo ao boato), caracterizando-se por

1 "Perfis e mundo de crianças e adolescentes em situação de rua na Grande Porto Alegre" foi uma pesquisa coordenada pela Fundação de Assistência Social e de Cidadania (FASC) desenvolvida pelo Laboratório de Observação Social IFCH/UFRGS (LABORS) em 2004, financiada pelo Banco Nacional de Desenvolvimento Econômico e Social (BNDES) para subsidiar políticas públicas pertinentes à questão.

Pesquisadora e professora do Programa de Pós-Graduação em História da UFRGS.

Estudos Ibero-Americanos. PUCRS, v. XXXII, n. 1, p. 175-188, junho 2006 
ser relativamente mais aberta a versões e imaginação, de quem testemunha e de quem registra por escrito. Trata-se de uma fonte de caráter etnográfico e histórico. Trama a exterioridade dos acontecimentos em representações coordenadas pela sintaxe (quem, o que, quando, como, onde, porque) ou manifestas em outras linguagens infraverbais, sensação e gesto, descritas pelo observador, freqüentemente através de metáforas. A partir dessa opção mais ampla, trabalhamos com a metodologia de grupos focais acessando crianças no seu espaço e em suas práticas, em seu foco, nas praças, sinaleiras e outros lugares em que se agrupam costumeiramente, indicados por mapeamento prévio. Algumas vezes usamos o gravador, que "fixa" o registro do testemunho tal como expresso pela pessoa-fonte, relativizando a intervenção do historiador. Em outras, limitamo-nos ao diálogo primordial.

Possivelmente, esse tipo de entrevista permita transitar com nossos entrevistados entre a situação de rua em que foram classificados, e onde fomos encontrá-los, para uma situação personalizante - identidade e quadros sociais da memória - (Sou como quem? Sou diferente de quem? Gostaria de ser como quem? Do que gosto de brincar). Nesse sentido, é sempre significativo lembrar os muitos meninos com quem já cruzamos, vestidos de Batman, de policial, de meninas com chiquinhas da Xuxa, ${ }^{2}$ ou tantos outros adereços da boneca Barbie. Isso, para não recair num vazio semântico em que as categorias identidade e memória sejam abstraídas do desejo, do afeto. Procuramos seus rostos, corpos e cenários, evitando o inquérito.

Sendo assim, associamos à metodologia de Grupos Focais procedimentos diversos: desenhar, cantar e gravar canções prediletas, auto-entrevistas em duplas que se revezam como entrevistador e entrevistado, entrevista por comentário a partir da narração de estórias ou roteiro temático, combinando registros etnográficos e históricos clássicos (diário de campo) e contemporâneos (gravação).

A entrevista por comentário consiste em extrair informações fazendo afirmações intencionais em vez de perguntas diretas. Os comentários podem variar, assim como ocorre com as perguntas, no grau com que são focados ou não e no seu nível de especificidade ou generalidade.

O gravador foi utilizado preferencialmente para manifestações espontâneas, como cantar músicas de sua escolha, gravar e ouvir o seu nome, falar sobre um sonho ou projeto, mandar uma

2 Apresentadora mais famosa de programas infantis na Rede Globo. Lança modelos e adereços que as crianças desejam intensamente. 
mensagem para alguém ou realizar auto-entrevistas. No grupo, as crianças escolhem suas duplas, revezando os papéis de entrevistador e entrevistado.

Utilizamos nossos relatos das entrevistas como sugestões para correlações de variáveis.

Realizei o trabalho de natureza mais propriamente histórica e historiográfica, selecionando estórias potencialmente capazes de propiciar a relação entre passado e presente, no modo proposto por Benjamim, a partir dos seguintes critérios: capacidade metafórica, difusão e recepção sobre a situação em estudo.

Através deles chegamos a Joãozinho e Mariazinha (Jacob Grimm - 1785-1863 e Wilhelm Grimm - 1786/1859), ao Pequeno Polegar (Charles Perrault - 1628-1703) e ao Patinho Feio (Hans Christian Andersen - 1805-1875). Trata-se de estórias que remontam à tradição oral do século XVI, que no século XVIII têm suas versões registradas em livro. Daí em diante, elas são constantemente reeditadas, recebem novas versões, originando filmes, desenhos animados para a TV, produções teatrais por todo o mundo, através dos tempos, constituindo historicamente o imaginário infantil.

Todas elas tratam, como é de conhecimento geral, de crianças entregues a própria sorte, excepcionalmente espertas, corajosas e autônomas, que se desenvolvem na luta com figuras ricas, poderosas e malévolas. Não só são capazes de salvarem a si mesmas como aos próprios pais. Originalmente não se destinavam às crianças, mas seus personagens eram crianças. Ao ultrapassarem a idade de sete anos, ainda no início do século XVIII, entre os setores populares, já eram vistas de modo especial as crianças que sobreviviam. Por isso, recebiam uma espécie de aura legendária por sobreviverem, uma vez que mais da metade morria antes dessa idade.

Tal quadro de mortalidade "fazia com que ... as crianças fossem consideradas pouco mais que animais" (PRIORE, 2004, p. 20), cuja força de trabalho deveria ser aproveitada ao máximo; também era comum o infanticídio e o abandono à própria sorte ou a entrega a Deus, como alternativa a extrema miséria dos pais: não alimentar mais uma boca.

Segundo Benjamin, o conto de fadas apresenta em seus heróis infantis uma dialética da coragem, entre a astúcia e arrogância (Benjamin, 1985 p. 215). Bettelheim, em A psicanálise dos contos de fada, sustenta que tais narrativas têm valor terapêutico, ensinando às crianças que "uma luta contra graves dificuldades na vida é inevitável". Acrescenta com grande otimismo: "se não fugimos assustados, mas enfrentamos resolutamente sofrimentos inespera- 
dos e muitas vezes injustos, dominamos todos os obstáculos e no final emergimos vitoriosos" (Bettelheim, 1996). Em contrapartida, vale considerar que há tudo na ficção de valor, menos uma resposta clara. Mesmo os contos de fada, com seu senso de justiça ingênuo, seu materialismo obstinado e seu espectro imaginativo por vezes estreito, raramente enviam mensagens sem ambiguidade...

\section{Narração de estórias}

A referência a produtos culturais preferidos (canções, jogos, desenhos, programas de TV, cantores e atores prediletos) indica quadros sociais da memória: heróis, modelos a serem imitados (personagens e seus protagonistas, atores, atrizes, cantores, grupos musicais) e sua variação da infância à juventude. Também permite uma abordagem indireta, protagonizada, isto é, em que o sujeito se expõe através do que deseja expor. A própria cultura constitui essa possibilidade.

Passamos a apresentar discursos das crianças em excertos ou citações, dos Diários de Campo ou transcritos de gravações, bem como a análise dos comentários, no modo anteriormente proposto.

Em abordagem na Praça XV, depois de uma série de peripécias, consegui contar estórias para duas crianças.

Filho de um presidiário e uma "pedida", isto é, pessoa jurada de morte, o "pequeno" (assim passamos a denominá-lo), de 5 anos mora com a avó. Eventualmente passa o dia com a mãe. Encontraa na Praça XV.

"Pequeno" chega ao que procura, usando todos os seus recursos, uma narradora só para si.

Conto "O Patinho feio", de Andersen. Ele segue a estória com atenção. Interrompe para rever ilustrações. Aponta o peru que bica o patinho "Ele é brabo", diz - detém-se novamente na ilustração em que o personagem sofre o ataque de caçadores. Aparecem as balas, um pato selvagem morto, outro chorando. Olhou atentamente, sem dizer nada.

Ao fim da história, não responde à pergunta - "o que mais gostaste". Volta às ilustrações. Pára no ataque aos patos selvagens e aponta para o patinho feio, no meio das balas. Também não responde à pergunta - "o que menos gostaste na estória". Diz: "conta outra".

Passo para "Joãozinho e Mariazinha", dos Irmãos Grimm. Ao atingir o momento em que os personagens são abandonados pela segunda vez, outro menino junta-se a nós. $\mathrm{O}$ pequeno resiste à 
idéia de recomeçar, mas o "recém chegado" (assim passei a denominá-lo) diz que não precisa, conhece a história. Antes de continuar, eu comentei:

- Parece que os pais pensam que os meninos poderiam achar uma vida melhor longe deles. É preciso ser muito valente para encarar a floresta.

- A minha mãe fez assim, diz o "recém chegado", baixinho.

No momento em que a bruxa prende as crianças, perguntolhe se gostaria de ler. Tímida e corretamente leu um parágrafo e passou-me o livro. Ficamos um bom tempo na ilustração em que Joãozinho aparece na gaiola e Mariazinha trabalha. Olhamos cada elemento.

- Ele não dá o dedo, é o osso, disse o "recém chegado".

- Foi a Mariazinha que jogou a bruxa no forno, digo. Ela é valente.

- Matou a bruxa, matou! diz "Pequeno".

Ao fim da história comento: as crianças é que trouxeram comida e dinheiro para os grandes.

Da bruxa! Fsssssh! Indicou o "Pequeno".

"Recém chegado" disse:

- A minha mãe não fez isso.

"Recém chegado" também mora com a avó e está na praça acompanhando a tia. Freqüenta a escola, $3^{a}$ série, com 10 anos.

Em abordagem na Casa de Acolhimento, Miriam contaria o "Patinho Feio" e eu faria a observação. Nessa casa, crianças são acolhidas por várias razões (necessidades especiais, situação doméstica crítica, drogadição etc.). Ficamos num dos quartos de dormir com sete crianças entre 6 e 10 anos. A educadora encarregada do grupo também estava presente. Há crianças com necessidades especiais. Estranharam muito e nos mobilizaram intensamente. Para viabilizar a narração, saí com eles em visita pela casa.

O relatório da colega registra as seguintes observações sobre a narrativa do Patinho Feio para o grupo que permaneceu no quarto: para o "que mais gostaram da estória"? "O patinho consegue fugir". Para "o que menos gostaram da história"? "O patinho não voltou para a casa dele, não ficou com a mãe dele" (cinco crianças). O patinho feio é a metáfora da diferenciação; do encontro de sua identidade e seus iguais, cisnes, aves reais; ruptura com uma comunidade a que não pertencia. Mas isto não sensibiliza essas crianças. Elas querem ter uma família; transformá-la num grupo aceitável. 


\section{Entrevista de expressão cultural.}

Eu e Juliana trabalhamos em ambiente aberto, mobiliado com mesa grande e cadeiras; buscamos uma aproximação plural com a comunidade da casa, incluindo os meninos especiais, através de recursos de expressão cultural (desenho e gravações).

Adolescentes (5) imediatamente sentaram-se conosco. Tanto eles quanto crianças maiores, de 11 e 12 anos, acolhem os meninos especiais. Entendem facilmente, o que não fala, através de sua gesticulação. Outro deles, que sempre pede a mesma coisa, é motivo de brincadeira. Desenhei mais de 20 vassouras de bruxa, fora as que seus parceiros desenharam para ele. Quando perdem a paciência, diante de sua insistência, gritam com ele sem raiva, só para colocar limite.

Conto que sou professora; os adolescentes devolvem contando suas "proezas" em sala de aula, brigas e gozações com professores, que terminam com vitórias e reconciliações, apesar de "ocorrências" que foram até ao Conselho Tutelar.

Todos desenham. A pesquisadora não identifica os desenhos com eles. Tem sua atenção disputada pelos especiais. A posteriori percebe que os adolescentes desenham quadrinhos com cenas de luta, parecem personagens de desenho animado. Escrevem seus nomes em várias letras diferentes, muito decoradas, como grafites ou pichações.

Contei sobre oficina de teatro e história que orientei numa escola, abrindo caminho para abordarmos a cultura (música, televisão etc.).

- Acho incrível como eles cantam e sabem as letras das músicas, adoro isto. Vocês também entram nessa?

A princípio, ficam encabulados. As adolescentes riem muito enquanto dizem - "Eles são lindos, sempre cantam na Xuxa", referindo-se a um grupo musical, "Os travessos".

- "Tu não vê a Xuxa ?"

Os adolescentes imitam as colegas. Um deles diz que o Faustão é melhor que a Xuxa. Preferem bandas, MTV e principalmente rap. Admitem ver novela, quando não há coisa melhor para fazer.

Um menino de 11 anos, que passa bastante tempo desenhando com Juliana, cantarola a música "Cuidem das crianças", da campanha do jornal Zero Hora, contra trabalho infantil e maus tratos. Perguntei se gostaria de gravar. Relutou um pouco antes de aceitar. 
Maltratar as criancinhas

É coisa que não se faz

Mesmo sendo o diabo

Disso nem eu sou capaz

Malvadeza com crianças

Isso só pode ser coisa

[...] do boi da cara-preta

Nem admito que falem

que maltrato meus boizinhos

eu sempre dei a eles

muito amor e carinho

não seja um monstro

por isso vamos cantar

o amor é a melhor herança

cuide das crianças ${ }^{3}$

Depois dele, as adolescentes se desinibem e aceitam cantar. Escolhem músicas românticas, "de ficar", sensuais, e de namoros que não dão certo, tais como SOS Paixão grupo (Os Travessos).

\section{SOS PAIXÃO}

Já me cansei de ficar por ai

Vagando sem destino a chorar por você.

Apostei tudo que tinha e perdi

Mesmo assim não desisti de ser feliz

[...]

SOS paixão

Diz o meu coração

Que não sabe não pode

Viver sem teu amor

Os adolescentes, mais velhos, têm admiração pelo primeiro cantor, porque ele "é bom de rap, pode até fazer um dele. Canta aquele...". O menino cantou. Tratava de drogas e violência. Entretanto, o coro dos acompanhantes tornou incompreensível a gravação. Mesmo de banho tomado senti nele o cheiro de "loló" ${ }^{4}$ É magrinho, aparenta menos idade do que tem. Na primeira abordagem não quis participar de nada. Neste momento, porém, canta, desenha, conversa.

Os primeiros comentários foram criados pelas crianças portadoras de necessidades especiais, rimos muito com as mais de 20

3 Música da Campanha da RBS TV, contra abuso e violência física e emocional sobre crianças.

4 Substância barata, que produz efeitos similares à maconha, produzindo estados de euforia, seguidos de depressão ou alheamento. Altamente tóxica. 
vassouras de bruxa desenhadas. Os demais surgiram com a narrativa de minha experiência em oficina de teatro e história numa escola de periferia: passaram a narrar suas transgressões escolares, proezas e brigas. Mostravam apreço pela escola, principalmente nas reconciliações; estimulados pelos fragmentos que lhes "reapresentei", transitaram para referências culturais: cantores, músicas preferidas, programas de televisão (Xuxa e Faustão) modelos de sucesso, beleza, sensualidade. Foi visível o espanto por eu não ver a Xuxa. Quem criou a passagem para o protagonismo foi o menino que cantarolava "Cuidem das crianças". Essa canção marcou uma campanha publicitária contra maus tratos; apareceu no contexto de primorosa animação envolvendo personagens de contos e lendas. Não havia criança que não soubesse a letra. Por sua vez, as meninas escolheram grandes sucessos, indicando recepção em todas as classes. É notável que os meninos terminaram fazendo um efeito de percussão para acompanhamento. Também fizeram questão que o companheiro cantasse seu rap.

Decorar espontaneamente, escolher para cantar, são indicadores de referências culturais arraigadas, que funcionam como quadros sociais da memória, representações permanentes que presentificam objetos de desejo e vivências passadas.

\section{Auto-entrevistas}

"D. Sou o Dudu, eu vou entrevistar o Fábio.

Quando tu tava na tua casa o que tu fazia com a tua mãe, tu ajudava a tua mãe?

F: Não! [enfático] Ficava brincando na rua.

D: E a tua mãe deixava tu ficá brincando? Quando ela pedisse pra tu faze alguma coisa tua fazia?

F: Eu fazia, mas só que depois eu pegava e ia brincá [baixando, escondendo a cabeça].

D: Quem é que te mandô tu vim pra Casa de Acolhimento? Tua mãe que te mandô tu vim ou foi tu que veio? [perguntou parece que já sabendo da importância da resposta].

F: Foi a mãe [bem baixinho], só que eu não sabia. Quando eu vi a Samanta, do Serviço Especial de Rua - SESR - me pegô e me trouxe.

D: Por que ela te trouxe? O que tu fazia? Tu desobedecia a tua mãe? [silêncio].

F: Eu ficava na rua [silêncio]. 
D: E por que ela te mandô tu vim pra cá? Por causa que tu incomodava muito ela? Desrespeitava ela? Não fazia o que ela mandava? F: Não! Por causa que eu tava na rua!

D: Tava cheirando um loló, se drogando, fumando um cigarro, ou o quê?

F: Tava!

D: E agora tu parô. Ta só fazendo uma das coisa: só fumando um cigarro, mas não cherando loló!

F: [vacilante] É.

D: Muito obrigado, já deu."

Dudu transita para um papel de assistente social. Ajudar tem, na linguagem da população "de rua" o sentido de pedir dinheiro. Freqüentemente os funcionários da FASC, em abordagem, usam a mesma expressão, associada a outras questões, para perceber a implicação dos pais na atividade de pedir. As crianças sabem que isso é proibido e procuram disfarçar. Fábio nega; esquiva-se dizendo que fazia coisas para a mãe e que depois brincava. O diálogo cai na ambigüidade entre ajudar em tarefas ou pedir dinheiro. Dudu em seus diferentes papéis abre alternativas que colocariam a mãe de Fabio numa situação difícil (deixar brincando, quer dizer, ficar na rua). Fábio sustenta sua versão do brinquedo. Dudu não esquece a pergunta clássica: Fábio veio por sua conta para a Casa de Acolhimento, ou por iniciativa de sua mãe? Sua mãe pediu a intervenção do "serviço de recolhimento"? Fábio retira a versão do brinquedo. Dudu insiste na relação com a mãe e Fábio reitera que ficava na rua, quer dizer, dormia na rua. Dudu transita para a droga (loló ou outra coisa). Dudu propõe um bom final. Fábio já estaria recuperado.

Fábio não desempenhou o papel de entrevistador, mas a entrevista anterior criou a transição para que Miriam Lemos o fizesse. Do bom final, Fábio recuperado, ela pergunta: - Dudu me diz se tu tens "algum sonho pro teu futuro".

D: Eu queria pedi desculpa pra minha mãe, por tudo que eu fiz de ruim e poder voltar para casa. pode?

E: E tu podes contar pra nós o que tu fizeste pra ela ou não

D: É por causa que eu pegava e eu saia de casa, quando ela precisa das coisa eu saia e ia pedi na sinaleira quando era pra ajuda pra ela.

E: E vocês já trabalharam bastante na rua? [sacodem positivamente a cabeça]. Tu ias pedir na sinaleira pra fazer o que com o dinheiro? 
D: Eu pegava juntava e dava pra minha mãe compra fralda pra minha irmãzinha que tem 7 mês e a outra tem 1 ano e 9 mês e depois a gente ajuntava latinha e papelão.

Dudu quer ir para casa, para o que der e vier; ele responde o que ele pensa que uma assistente social gostaria de ouvir; e assim também expressa o que ele tem como valor, como boa conduta: ajudar a mãe. Miriam transita nessa resposta; abre-a, do valor para o comportamento, a ação - "podes ou não podes contar o que tu fizeste pra ela". Dudu transita para expor o proibido. A mãe teria apelado ao "serviço de recolhimento" porque ele pedia na sinaleira para ajudá-la. Mas se fosse assim, ele teria entregado o dinheiro a ela. Miriam transita para dentro dessa ambigüidade ao perguntar o que fazia com o dinheiro ganho na sinaleira. Dudu retorna com dar dinheiro para a mãe comprar fraldas. A mãe de Dudu teria essa atitude se ele entregasse o dinheiro? É possível que a mãe recorresse ao dinheiro da sinaleira em situações restritas. Talvez Dudu tivesse abandonado a escola para pedir, ou estivesse pedindo para consumir loló e não para ajudar a mãe, para ser um "Joãozinho" ou um "Pequeno Polegar" dos contos de fadas...(?) A entrevista sugere culpa, ambigüidade e dissimulação.

\section{Imaginário e memória}

Os discursos sugerem referências sociais e culturais.

Valorização da mídia - sinalizada por expressões tais como "tu não vês a Xuxa"(?); menção espontânea e recorrente à apresentadora, primeiro madrinha, depois rainha dos baixinhos, menção ao animador de auditório "Faustão"; atitudes tais como decorar as letras das músicas, reproduzir o modo de cantar, dançar e movimentar-se dos artistas prediletos, modelos a serem imitados.

Valorização da Família - sinalizada pela crítica ao "patinho" que deveria reencontrar a mãe, voltar para casa pela vibração com o retorno de Joãozinho e Mariazinha, trazendo o tesouro da bruxa para os pais; pelas representações de Dudu e Fábio na Casa de Acolhimento.

A partir desses sinais priorizamos uma leitura da Valorização da Família, pouco importa se múltipla, constituída por diferentes relações ou por situações de circularidade das crianças entre casas de outros parentes ou amigos.

Se a valorização da família constituir referência cultural para a população em estudo, é preciso identificar e trabalhar com variáveis indicativas. Selecionamos a correlação entre "faixa etária e 
volta para a casa da família ou conhecidos". O resultado indica que $75 \%$ da amostra volta para casa. As crianças de 7 a 11 anos, correspondem a $89,6 \%$ dos que voltam (ver tabela 1). Admitindo-se que este seja um perfil de valorização da família, as crianças ditas de rua têm vínculos familiares como qualquer outra criança. Possivelmente, trata-se de vínculos fortes, pois $56 \%$ dos adolescentes entre 15 e 18 anos também voltam para casa. Com isso, relativizase uma imagem corrente sobre a situação de rua: não ter família ou fugir dos maus tratos e exploração de quadrilhas de pais perversos. Uma situação possível é de que pais explorem os filhos mantendo, não obstante, vínculos afetivos com eles.

Se ajudar em casa é um valor para as crianças, é pertinente esperar uma correlação entre o que fazem do dinheiro que ganham e faixa etária. Ela mostra que 43,13\% das crianças entre 7 e 11 anos entregam tudo que ganham para os pais, enquanto $29,9 \%$ entregam apenas parte, o que é considerável, tanto para indicar o compromisso como para indicar uma parcela que desfruta de maior liberdade para administrar seu ganho. É significativo que 23\% dos adolescentes entre 15 e 18 anos entregam todo seu dinheiro para a família e $36 \%$ entreguem parte do dinheiro para a família.

Por outro lado, é preciso considerar o custo dessa "ajuda", suas implicações para o imaginário e a identidade dessas crianças. Isso nos leva a correlação entre atividade principal na rua e faixa etária (ver Tabela 2). Ela indica que "pedir" é a atividade mais praticada por crianças entre 7 e 11 anos. As crianças que vivem por si mesmas ou "ajudam os pais", os Joãozinho e Mariazinha, "pedem". Mas têm pavor do mendigo, que para eles é o velho, sem possibilidade de mudar de vida. O pedir, entretanto, é uma sociabilidade, um ritual, uma forma sistemática de relacionar-se com o outro, para essa população, entre 7 e 11 anos.

As crianças expõem sua fragilidade e desvalia à "indiferença flutuante" que se confirma ou pela rejeição dos que viram o rosto para não vê-las, ou pela piedade dos que dão a moedinha. Por isso mesmo, o pedir é a atividade mais praticada pelas crianças. No ato de abordar para pedir, o sujeito investe na desvalia na dissimulação e na esperteza, gerando um quadro social de memória que interfere na percepção do mundo e de si mesma. Madura geralmente, em torno dos sete anos de idade para ter prazer com atividades de especulação e criação, típicas da aprendizagem, criando uma memória de auto-afirmação pelo prazer de aprender, a criança que "ajuda" está limitada pela estratégia do "pedir" ou do "vender". 
Do ponto de vista de apreciação de produtos culturais típicos da modernidade, não há dúvidas de que as crianças na rua estão integradas: mídia, jogos eletrônicos, música de ampla recepção entre todos os segmentos sociais, programas, artistas etc. Afetivamente, valorizam a família encarando como valor ajudá-la.

Onde está a diferença? Outras crianças poderão ter problemas de aprendizagem por uma série de razões, mas não por terem de se sustentar ou "ajudar" em casa "pedindo" ou "vendendo amendoins" na sinaleira. Aí está, portanto, uma diferença entre elas e outras crianças.

Compartilhar esse ritual de não valor com outros iguais, eventualmente cria uma identidade social dos "de rua", contrastiva face ao outro: os "de bairro", os "de dinheiro" etc. Numa sociedade apresentada como a grande família que ajuda, comandada pela mídia, envolvendo artistas e apresentadores de maior sucesso, o pedir representa-se natural e legítimo - "tia me dá uma moedinha".

Tabela 1

Volta para casa da família ou conhecidos

Faixa etária (quando o 100\% está na coluna, compara-se linhas)

\begin{tabular}{|c|c|c|c|c|c|}
\hline \multirow[b]{2}{*}{$\begin{array}{l}\text { Quando volta para } \\
\text { casa }\end{array}$} & \multicolumn{4}{|c|}{ Faixa etária } & \multirow[t]{2}{*}{ Total } \\
\hline & $\begin{array}{c}\text { De } 0 \text { a } 6 \\
\text { anos }\end{array}$ & $\begin{array}{c}\text { De } 7 \text { a } \\
11 \text { anos }\end{array}$ & $\begin{array}{l}\text { De } 12 \text { a } \\
14 \text { anos }\end{array}$ & $\begin{array}{c}\text { De } 15 \text { a } 18 \\
\text { anos (in- } \\
\text { completos) }\end{array}$ & \\
\hline \multirow{2}{*}{ Todos os dias/noites } & 3 & 60 & 74 & 50 & 187 \\
\hline & $100,0 \%$ & $89,6 \%$ & $84,1 \%$ & $56,2 \%$ & $75,7 \%$ \\
\hline \multirow{2}{*}{ Às vezes na semana } & 0 & 1 & 2 & 7 & 10 \\
\hline &, $0 \%$ & $1,5 \%$ & $2,3 \%$ & $7,9 \%$ & $4,0 \%$ \\
\hline \multirow{2}{*}{ De vez em quando } & 0 & 1 & 4 & 8 & 13 \\
\hline &, $0 \%$ & $1,5 \%$ & $4,5 \%$ & $9,0 \%$ & $5,3 \%$ \\
\hline \multirow{2}{*}{ Nos finais de semana } & 0 & 1 & 1 & 7 & 9 \\
\hline &, $0 \%$ & $1,5 \%$ & $1,1 \%$ & $7,9 \%$ & $3,6 \%$ \\
\hline \multirow{2}{*}{ Varia muito } & 0 & 2 & 2 & 2 & 6 \\
\hline &, $0 \%$ & $3,0 \%$ & $2,3 \%$ & $2,2 \%$ & $2,4 \%$ \\
\hline \multirow{2}{*}{ Não volta } & 0 & 2 & 5 & 15 & 22 \\
\hline &, $0 \%$ & $3,0 \%$ & $5,7 \%$ & $16,9 \%$ & $8,9 \%$ \\
\hline \multirow[t]{2}{*}{ Total } & 3 & 67 & 88 & 89 & 247 \\
\hline & $100,0 \%$ & $100,0 \%$ & $100,0 \%$ & $100,0 \%$ & $100,0 \%$ \\
\hline
\end{tabular}


Tabela 2

O dinheiro que ganhas

Faixa etária Crosstabulation

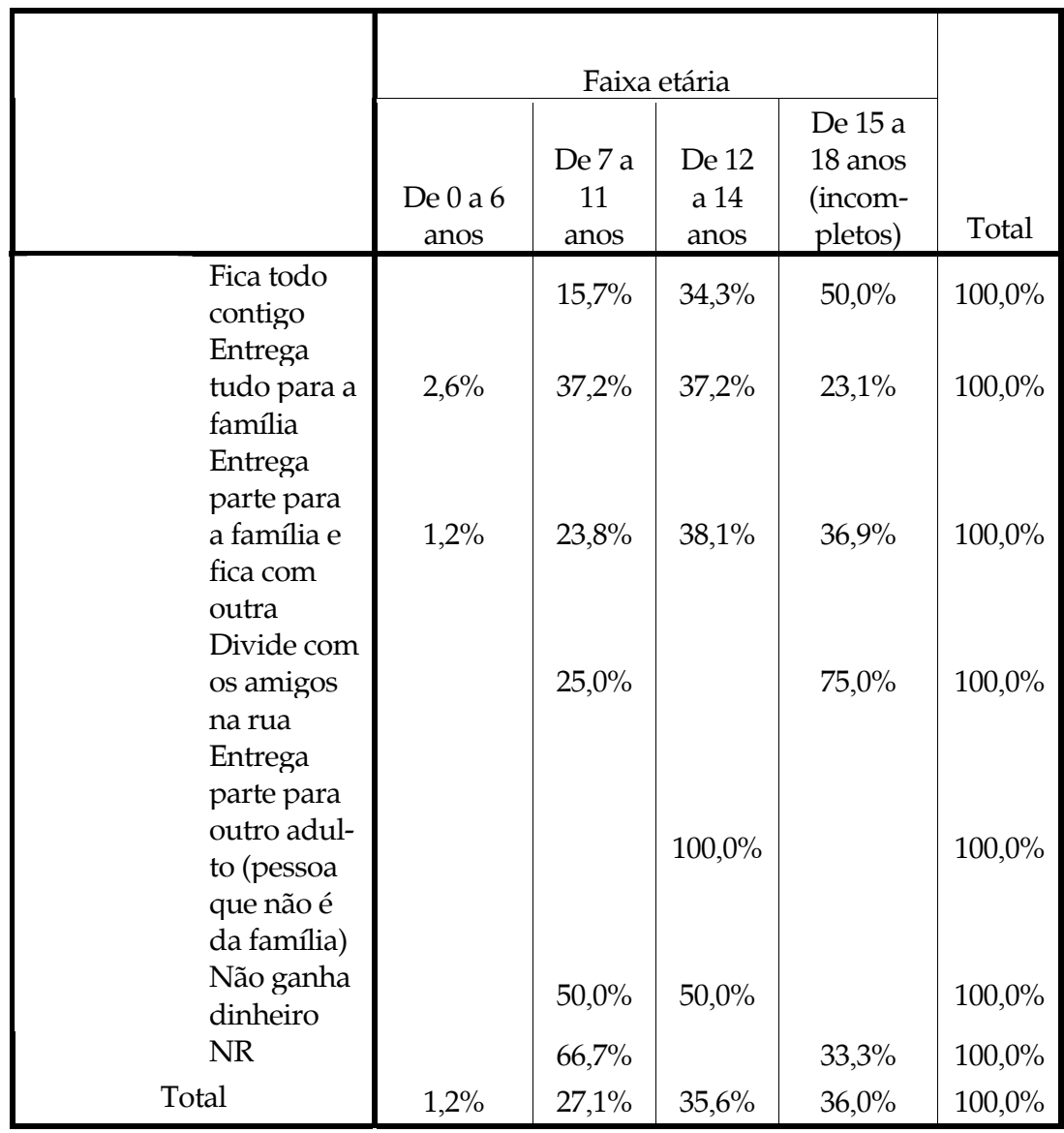




\section{Referências}

TATAR, Maria. Contos de fadas. Edição comentada e ilustrada. Rio de Janeiro: Zahar, 2002,

DEL PRIORE, Mary (Org.). História das crianças no Brasil. São Paulo: Contexto, 2004.

BETTELHEIM, Bruno. A psicanálise dos contos de fada. São Paulo: Paz e Terra, 1996.

BENJAMIN, Walter. Magia e Técnica. São Paulo: Brasiliense, 1985.

HALBWCHS, Maurice. A memória Coletiva. São Paulo: Centauro, 2004.

GHELEN, Ivaldo; MAGNI, Claudia; LEMOS, Miriam; MARTINI, Maria Luiza. Perfil e mundo de crianças e adolescentes em situação de rua. Porto Alegre: FASC e LABORS/UFRGS, 2004.

SNOW, David; ANDERSON, Leon. Desafortunados, um estudo sobre o povo da rua. Petrópolis: Vozes, 1998. 